\title{
A Mentor's PATH: Evaluating how service users can be involved as mentors for social work students on observational practice placements
}

\author{
Jill MacSporran ${ }^{1}$
}

\begin{abstract}
This paper will explore the experience of service user involvement in social work education, examining the challenges of involving 'seldom heard' service user voices. Over a six month period, a group of four people with learning disabilities were supported and enabled to take on an assessment role as Mentors for four first year BA(Hons) Social Work students at the University of the West of Scotland. The article will focus on an evaluation of this pilot project and will outline the partnership work between the university and placement agency in planning, preparing, and supporting the mentors to carry out their role in supporting students on placement and assessing their communication skills, value base and readiness to practise. Central to the planning process was the use of PATH - a person centred planning tool. The evaluation will detail the crucial role played by the support staff in the placement agency, without whom this project would not have been possible.

The evaluation was carried out using a mixed methods approach and embraced the principles and values of participatory action research. The evaluation provides insight into the experiences of the mentors, the students and support staff, and demonstrates that with the right support in place, and with commitment to thorough planning and preparation, seldom heard service users can be meaning fully involved in social work education.
\end{abstract}

Keywords: service user involvement; social work education; partnership; practice learning; seldom heard user voices.

\section{Lecturer in Social Work, University of the West of Scotland}

Address for correspondence: School of Social Sciences, University of the West of Scotland, The Crichton Campus, Dumfries DG1 4ZN. jill.macsporran@uws.ac.uk

Acknowledgements: Grateful thanks to Anne Ritchie, retired senior lecturer at UWS, without whose original idea, insight, guidance and support, this project would not have been possible. Enormous thanks also to the project mentors and staff whose enthusiasm and commitment has been inspiring. 


\section{Introduction}

This paper outlines the implementation and evaluation of a pilot project which was a partnership between the University of the West of Scotland (UWS) and a third sector provider of support services for adults with a learning disability.

Traditionally, BA(Hons) Social Work students are supported on short observational placements in years one and two, by a mentor who provides shadowing experiences and supports student learning through observation and enquiry. The placement agency provides supported living services for adults with a learning disability, as well as providing a supported employment service. Whilst negotiating with the agency managers about these placements, it became clear that this would be a great opportunity to enable service users to become involved in that mentoring role, via the supported employment service. This pilot project supports the aims of the agency in promoting independence and valued social roles for their service users, and UWS were keen to support the idea of involving service users in this way, especially as adults with learning disability are an often under-represented group in service user involvement, especially those with communication challenges (Beresford, 2013). Hearing, and listening to, seldom heard user voices was to be a challenge in this project and it was clear from the outset that support workers and job coaches would need to be involved, to enable the service users to be fully supported to take on this role, and overcome some of the structural barriers to participation. Beresford (2013) identifies a number of barriers to service user involvement, including tokenism, stigma, language, confidence and self-esteem. He also outlines the importance of ensuring the necessary support is put in place to help service users overcome these barriers, such as enabling access to involvement; building support to ensure confidence building, development of skills and empowerment; working collectively; financial benefits.

The project embraced the principles of participatory action research, as it fits into the tradition of emancipatory research (Alston and Bowles, 2003). In contrast to evidence based practice which assumes a managerialist view of knowledge that embraces quantitative research (Petr and Walter, 2009), participatory action research is committed to involving the people who are most affected - in this case, students and service users:

It challenges the traditional power imbalance between the researcher as 'expert' and research participant as 'passive subject' and is highly compatible with anti discriminatory and anti oppressive practice. (Whittaker, 2009, p12)

\section{Definition of the project}

This project introduced a new and innovative way of supporting and assessing 
BA(Hons) Social Work students in year 1 of their course, whilst on a ten day observational practice learning opportunity. People who use services would take on the role of mentor to a student, a role which has previously always been carried out by an experienced member of social work/care staff. It would involve UWS staff working in partnership with service users and staff from the placement agency. The project would involve four year 1 students from a cohort of 28 , who were matched to the agency on the basis of previous experience, learning needs and geographical location. The agency identified four service users whose participation was voluntary and who were willing to take on the role of mentor to the four students. In line with ethical practice, they could withdraw at any time and support would be provided throughout the project to ensure they were fully supported emotionally and practically. To ensure clarity in this paper, they will be referred to as project mentors, in order to differentiate from other (staff member) mentors, notwithstanding the fact that their role would be the same.

\section{Context of the project}

Social work is a profession whose values embrace empowerment and inclusion, and for some time service users have been involved in many aspects of service provision and evaluation. More recently the Changing Lives report (Scottish Executive, 2006) highlighted the need for greater collaboration and involvement of the people who use social work services, either as a user or carer. The report states

They [service users and carers] will demand a more personalised approach, much greater involvement at all levels and more transparency about the services available. Because people are becoming better informed they have growing expectations that services will be delivered where and when they want them. (Scottish Executive, 2006, p.20)

The emphasis on this involvement was to move increasingly away from a tokenistic notion of user involvement to a much more empowered and informed way of contributing to decision making and service provision. As part of this drive for change, universities have also had to embrace the idea of service user involvement in supporting the way that Social Workers are trained and educated. Changing Lives also states:

Developing the practitioners of the future won't happen overnight and will involve active partnership between education and practice. Universities and Service Providers will need to work together in a planned way .....' (Scottish Executive, 2006, p.56)

The Framework for Social Work Education in Scotland (2003, p.15) states that 
programme providers should ensure that 'Policies and procedures for assessment must include effective and appropriate ways of meeting the requirements of key stakeholders in social services .... key stakeholders include people who use services, carers and employers.

This project would enable the people who use services to work in partnership with the university and the agency which provides their support services, and to be involved in influencing the knowledge and attitudes of social workers at the very outset of their professional training. Levin (2004, p.2) recognises the need for service users and carers to be involved in social work education as it offers 'a major opportunity for a new generation of social workers to gain a grounding in service users' and carers' experiences and expectations from the very start of their training and careers.'

\section{Review of the Literature}

Service user knowledge has now become embodied in both policy making and individual practice. Service user knowledge has grown out of both personal and collective experience of being on the receiving end of social work services, and this experiential knowledge has helped to shape policy and practice (Beresford, 2000). Service user knowledge is much more than just telling their story (Anghel and Ramon, 2009), and although that learning is powerful, it is important that service users' viewpoints and experiences are utilised in more diverse ways, for example in assessing students (Duffy et al., 2011), in co-teaching (Stevens and Tanner, 2006), and in design and delivery of programmes (Benbow et al., 2011).

Molyneux and Irvine (2007) describe their work in consulting with a service user and carer reference group to explore how an Approved Social Work Programme in the north of England could improve and integrate the involvement of users and carers in the delivery of the programme. Skilton (2010) reviews work carried out at another English university to evaluate the development of an 'experiential learning exercise' as part of an academic module in the first year of the degree programme. This work describes the advantages of involving 'experts by experience' in helping students develop skills, knowledge and values of social work and to assist in the early development of reflective practice.

Anghel and Ramon (2009) present a European perspective on this subject and describe their work in introducing a systematic involvement of service users and carers in the delivery of an undergraduate programme. They describe their case study as an example of 'UK innovation in social work education with the potential to radically change social work practice' (Anghel and Ramon, 2009, p.185).

Brown and Young (2008) describe their work in developing a learning programme, 
in partnership with a social care skills agency, to enable service users and carers to develop skills and build capacity in contributing to social work education.

All these writers acknowledge the importance of avoiding tokenism and describe the challenges of partnership working with users and carers to promote a shared value base of respect, equality, partnership, inclusion and empowerment. They also note the important benefits to users and carers, as well as the benefits to students' learning experiences, especially in reflective practice. They all acknowledge the power differential that exists between users and carers and professional staff and the resulting challenges in partnership working.

A significant difference with this project, is that it is located in the agency, the practice learning opportunity and the service users' life space, rather than within the university setting, thus enabling a real shift in the power base. Our project mentors have the control over the students' learning experience, and are more able to create an experience which enables the student to fully understand their lives, how they are supported, to allow them to be in their life space, and how they are able to take on valued roles within this learning process.

Social work education needs to be concerned with the balance between the acquisition of professional and theoretical knowledge and service user and carer knowledge, with the acknowledgement that service users and carers are 'experts' in their own lives (Brown and Young, 2008). It is about more than just telling their story; they can have a really important role in the early development of good practice in communication, reflective practice and ethical practice. 'When the power differential is reduced and the service users and carers feel respected for what they can offer, they are more able to share their perspective' (Anghel and Ramon, 2009, p.187)

Trevithick (2008, p.1214) writes about the importance of locating service user knowledge within the same framework as professional knowledge, and the need to integrate practical and theoretical knowledge - 'knowing about and knowing how'.

\section{Rationale including intended outcomes}

The purpose of this project was to provide real opportunities for the inclusion of service users in the support and assessment of student practice learning experiences, which would lead to greater empowerment for the project mentors and at the same time, enhance the learning of students. Currently, within the undergraduate programme, service user and carer views are sought as part of the formative assessment process for students in all years of the programme, so the views of the people who have been helped or supported by the student contribute to the assessment of their competence and readiness for professional practice.

In this project, the intended major difference would be that the service user would provide direct support to the student and gather assessment feedback from 
other people within the agency, creating a closer and more meaningful involvement for service users and a powerful and insightful learning experience for the student. The feedback from mentors is used to inform the summative assessment process, and in year 1 observational placements, the students are assessed via an academic assignment, and mentor feedback is used to assess readiness to practice and professional attitudes and behaviour.

The intended outcomes for project mentors would be: an increased feeling of empowerment and having a valued role; increased self confidence; opportunity to develop skills; being paid to do a professional task; and to enhance the profile of the agency.

The intended outcomes for students include: an opportunity to learn directly from the people who use the services in which they are placed; to understand the importance of service user views and to see them as experts in their own lives; to understand the power dynamic within the helping relationship; to meet the learning outcomes as defined for their observational practice learning opportunity.

Outcomes for organisational learning include: an opportunity to improve partnership working and recognise the value of service user contribution to social work education.

\section{Implementation of the project}

The project planning was carried out over a period from June 2011 to the start of the placement in January 2012. Following the 10 day placements, the evaluation work was carried out until April 2012.

We used an empowering planning method called PATH, and this was developed by the group of project mentors, their support workers, job coaches and academic staff.

PATH is a person centred planning tool, which involves partnership working and involves all stakeholders in the planning process. (Sanderson et al, 1997)

PATH is a way for diverse people who share a common problem or situation to align... their purposes .... their understanding of their situation and its possibilities for hopeful action .... their action for change, mutual support, personal and team development and learning.' (Pearpoint, O’Brien, Forest cited in Sanderson et al (1997, p.120.)

The goals (or 'dreams') were identified by group members, and tasks, roles, responsibilities, timescales and resources were identified and a clear plan or process towards meeting the 'dreams' was formulated. Molyneux and Irvine (2007, p.297) comment that service users are not always seen as 'experts', and therefore lack the influence of professional staff and note 'the importance of acknowledging and clarifying these issues from the beginning'. This would be a crucial part of 
the planning process, to ensure that there was a clear agreement about roles and responsibilities and an understanding about the shared decision making in terms of assessment of student learning.

During this process, it became very clear how easy it is to make assumptions about people based on their disabilities. It was easy to assume that the project mentors would be fairly limited in their cognitive function because of their learning disability, but care had to be taken to avoid prejudice and stereotyping the mentors as 'less able'. It was a very humbling experience and one which enabled UWS staff to be the learners in this situation and on reflection realise how powerful the learning experience would be for students.

As part of the project planning, there were specific tasks to complete and these included the following:

- The mentors needed a list of the students' learning outcomes - the wording used in the student handbook was less than helpful, using academic jargon, and so changes were made but care was exercised to ensure that the balance was right and that we avoided making it too simplistic or patronising. They were given a draft copy of these outcomes in advance and consulted about the appropriateness of them to ensure that the learning outcomes were accessible to the project mentors. Understanding and ownership for the material would be pivotal in helping them assume the responsibility for the assessment process, and their role within it. Warren (2004, p.83) discusses the importance of genuine participation and an important area is 'understanding their [service users] preferred ways of involvement, and accommodating alternative ways of working and communicating.'

- It was also necessary to provide some information about the areas of assessment which we particularly wanted the project mentors to focus on. For year 1 students at this stage in their learning, we needed feedback on their communication skills; their ability to engage with service users and whether they demonstrated the personal qualities one would expect from a Social Worker. During the planning stage, we had a lot of discussion about how the feedback would be gathered, given that the mentors did not all have literacy skills, and they all had different communication styles. It was agreed that they would gather assessment feedback verbally, either face to face or by telephone, using a checklist that they had devised themselves. In order to record the feedback we discussed using information technology to record the feedback, either using digital voice recorders or video cameras. Communication would be crucial to the success of this project and also to the success of the assessment process and the evaluation of the pilot. (Warren, 2004)

- Working with support staff and job coaches would ensure that the project mentors had adequate support and time to develop the skills they would require to carry out this role. Various ways were devised to do this including helping 
them to think about the questions they would ask other service users in order to gather feedback; preparing personal presentations to give to students at their induction, which would enable them to 'tell their story' and help students understand their perspectives; support the planning of a timetable of activities for the ten day period to ensure students had the opportunity to meet other service users and to understand the work of the agency and therefore able to meet their learning outcomes.

- The four project mentors were invited to attend mentor training alongside other mentors. This involved careful consideration of how to structure the training programme to ensure equity and inclusion for the project mentors. Due to other commitments only two of the four project mentors were able to attend the training, and after discussion, we agreed that they would attend for the second half of the training session. There were several reasons for this. The first half of the session would cover topics which were all areas we had previously covered in our planning meetings as part of the PATH process. It would also mean that the two mentors, who are both wheelchair users, would avoid having to sit for an uncomfortably long time. The two project mentors and their support staff, along with a job coach from the Agency all participated in exercises to enable mentors to think about different methods of communication, the centrality of good communication to the learning process, and the importance of professional boundaries when working with vulnerable people. Again, careful consideration was given to the content of the training programme to ensure that it met the needs of all the mentors and did not marginalise the two project mentors. Some changes were made to some of the group exercises, to enable their full participation.

Another participative exercise involved discussion about a variety of issues which would lead people to consider values and professional boundaries. This exercise proved to be the most powerful learning experience of the day, for the other mentors in the room who were all social workers/care staff. The two project mentors were able to give their perspective to the discussion and clearly gave the other mentors an opportunity to examine their own assumptions and prejudices.

It was also important to ensure that the four students who were attending these placements were fully briefed about the nature of the pilot project. Permissions were sought from the student group, and they were provided with a briefing session before the placement, which revisited their learning outcomes and the skills, values and knowledge required of them, helping them to understand the values surrounding partnership working. They also had to feel empowered and not feel they were part of an 'experiment'. Like all students about to undertake their first practice learning opportunity they were nervous, but excited that they were being part of this new development. At the end of the placements we held a focus group discussion on the outcomes and to evaluate the process. 


\section{Evaluation of the project}

In order to assess the impact of the project and to determine whether it met the planned outcomes, an evaluation was carried out using both quantitative and qualitative methods.

Self-efficacy questionnaires (Parker, 2004) seemed like a helpful way to evaluate the students' learning from this project. By having a measure of their confidence in carrying out a range of social work tasks, prior to the placements, and by making the same measurement post placement, it was possible to evaluate whether the practice learning opportunities had helped these first year students to develop their confidence in a number of key areas, or indeed if the realities of practice had reduced their confidence levels (Fig.1). The students were asked to identify themselves on the questionnaire, so that students could be identified against their particular setting. This meant that the results from the four students on the project could be compared against the rest of the cohort, but also that the remaining questionnaires would also be a useful quality assurance tool to ensure the placements were meeting the learning needs of all the students. Appropriate permissions were sought from the students prior to completion and participation was voluntary.

After collating and analysing the data from the self efficacy questionnaires, (24 of 28 returned) it was clear that all the students had experienced an increase in their confidence in all areas. When the results from the four project students were examined and compared with rest of the group, their increase in scores was higher than the rest of the cohort in most areas, which would indicate that their learning opportunity with service users as mentors had significantly raised their confidence in carrying out the range of tasks. A significant point though, was that there were two areas where the project students' scores were lower - 'Understanding how discrimination and disadvantage affects peoples' lives'; and 'use your mentor as a support and guide through the practice learning process'. On closer examination of the individual questionnaires, one student had rated no difference in their confidence in these two areas, which brought the average score down, but the reason for this may well have been that the student had previous experience of working with this service user group, and therefore felt confident at the outset.

The four students were invited for focus group interviews post placement, to have semi-structured discussions about their experiences, not only of the placement learning but of being mentored by a service user. The focus group discussion highlighted the positives and negatives of the experience, and also shed light on the anomalous result from the questionnaires. It became clear that one of the project mentors had to resign due to health issues and the new mentor (who had been involved at short notice) had not been able to participate in all the planning meetings, and therefore was less prepared and possibly less skilled than the other project mentors who had full involvement in the process. This might account for the student feeling less well supported by her mentor. 
Fig.1 Self Efficacy Questions

\begin{tabular}{|c|c|c|c|c|c|c|c|c|c|c|}
\hline $\begin{array}{l}\text { How confident do you feel that you can } \\
\text { successfully do the following:- }\end{array}$ & & & & & & & & & & \\
\hline $\begin{array}{l}\text { Communicate and engage with service } \\
\text { users }\end{array}$ & 1 & 2 & 3 & 4 & 5 & & 7 & & & 10 \\
\hline $\begin{array}{l}\text { Apply theoretical models to practice } \\
\text { experiences }\end{array}$ & 1 & 2 & 3 & 4 & 5 & 0 & $t$ & & & 10 \\
\hline $\begin{array}{l}\text { Work with other staff in the practice } \\
\text { learning setting }\end{array}$ & 1 & 2 & 3 & 4 & 5 & & & & & 10 \\
\hline $\begin{array}{l}\text { Understand the needs of the service user } \\
\text { group }\end{array}$ & 1 & 2 & 3 & 4 & 5 & & & & & 10 \\
\hline $\begin{array}{l}\text { Understand how discrimination and } \\
\text { disadvantage affects people's lives }\end{array}$ & 1 & 2 & 3 & 4 & 5 & 0 & & & & 10 \\
\hline $\begin{array}{l}\text { Manage your feelings if you are working } \\
\text { with people experiencing emotional and } \\
\text { psychological distress }\end{array}$ & 1 & 2 & 3 & 4 & 5 & 6 & 7 & 8 & & 10 \\
\hline $\begin{array}{l}\text { Use your mentor as a support and guide } \\
\text { through the practice learning process }\end{array}$ & 1 & 2 & 3 & 4 & 5 & 6 & & & & 10 \\
\hline $\begin{array}{l}\text { Understand how services can empower } \\
\text { people and promote anti oppressive } \\
\text { practice. }\end{array}$ & 1 & 2 & 3 & 4 & 5 & & & & & 10 \\
\hline
\end{tabular}

On reflection, this highlighted the benefits of a mixed method approach as the qualitative and quantitative results were able to support the findings from each approach.

The students felt the experience had been very positive and one of the most important learning outcomes for them was realising the importance and challenge of communicating in different ways. They all recognised that they had different experiences as their mentors all had different communication styles, which in turn helped them to understand values around individuality and uniqueness. Comments from students included:

I learned about the challenges of communicating in different ways.

I think it helped me to build my confidence and my communication skills.

They were very impressed by the ethos of the agency and the person centred approach employed there. 
I was able to experience firsthand what they [users] expected from the agency, what they felt their needs were, and how they were being met.

They all felt the mentors provided an excellent learning experience, although they acknowledged that some needed more support than others. In some cases, particularly for the mentor who had joined the process later, the support staff had a much more significant role in supporting the student's learning. This meant that the students were able to experience the power differences, and noted how different the experience was if the support staff felt the need to step in and in some cases, although well-intentioned, take over.

Significantly, the students could also realise the benefits for the mentors, recognising the rise in their self-esteem and the importance of having a valued role. Most of their learning had been as a result of direct and consistent contact with the people who use services, working in their life space and hearing their testimony.

I have a better understanding of what service users need and expect from social workers - they feel they don't see their social worker often enough and this impacts on the effectiveness of the working relationship.

Students also reflected that this had been an important experience at the start of their learning journey and could see how it might influence future practice.

I will carry this experience to my future placements.

A focus group with project mentors and agency support staff also took place, to understand the impact of the project from their perspective. In consultation with the group, it was agreed that we go back to the PATH, and use this as a reviewing tool. This allowed us to focus on the identified 'dreams' and led to discussion about how/whether the dreams were realised. Given that this had been a new experience for everyone, the feedback from mentors was very positive. They were able to identify things they might do differently the next time, e.g. make some changes to the practical elements of the learning programme, to allow students to spend more time with fewer service users. They felt the 'dreams' had all been achieved but put particular emphasis on the following: gaining in confidence, learning new skills, feeling involved, feeling more independent, having a good reputation for themselves and for the agency, and getting paid for their contribution - having a 'job'. Mentors comments include the following:

It really helped me be more confident.

I enjoyed helping the students to learn about my life. 
My support worker was a great help.

I got paid for the job - that made me feel important.

It was a lot of work. Next time we might not arrange so many visits.

Skilton (2010) and Beresford (2013) both discuss the importance of recognising the expertise of service users, and at the same time address the potential for power imbalance and discrimination, by negotiating a satisfactory payment rate. In this project the agency receives the usual daily placement fee for each student, and a negotiated amount was paid directly to the project mentors, administered via their supported employment project.

Support staff reflected on the challenges of helping project mentors to gather feedback from other service users, and said

It was a challenge at times to help the mentors gather the feedback - we could make more use of IT in future.

They reported that the project mentors had all taken their role very seriously and felt the project had been a huge success, giving them an important opportunity to influence learning at the start of the students' journey.

All mentors are required to complete and return feedback forms following the observational practice learning opportunities. Initial written feedback was collated on the usual feedback forms by a member of the agency staff, but other feedback would follow later, coming directly from the project mentors in the form of voice recordings and video recordings. Students are also asked to complete a feedback form which is used as a quality assurance tool, and together with the self-efficacy questionnaires and focus group feedback the data was triangulated to fully evaluate their experiences, and ensure reliability and validity. (Alston and Bowles, 2003).

In June 2012, three of the project mentors, their support staff and UWS staff presented a workshop at a service user conference ("Real Lives, Real Difference", University of Stirling). Following a brief outline of the project, a round table discussion illustrated the project experience from the mentors' perspective and they had an opportunity to express what the project had meant for them, highlighting their positive experiences.

\section{Conclusions}

In discussing the evaluation of the project and its impact on learning, it seems clear that the outcomes have been achieved. Carpenter (2005) and Brown et al (2008) discuss the classification of educational outcomes devised by Kirkpatrick (1967, cited in Carpenter, 2005) and later elaborated by Barr (2000, cited in Carpenter, 
2005), as a useful framework to assess the effectiveness of educational programmes at four different outcomes levels:

- Level 1 measures the learner's reactions, and it is clear from the evaluation described above, that the students' learning has been satisfactory and not only achieved their stated learning outcomes, but has further enhanced their confidence and competence in practice learning. Significant learning has also taken place for all the stakeholders in the project, including academic staff.

- Level 2 considers the changes in attitudes and perceptions and the acquisition of knowledge and skills. The students have responded positively, acknowledging the acquisition of knowledge from their mentors and their support staff, and have acquired a greater degree of confidence and skills in communication. Most importantly, this model of learning has highlighted the issue of power differentials in the helping relationship, and the need for equity, inclusion and empowerment in partnership working.

- These practice learning experiences, supported by service users have allowed the students to achieve level 3 - Changes in behaviour - by assisting in their transformational learning experience, and helping the students to transfer this important learning experience into future practice placements.

- Level 4 relates to changes in organisational practice, and the benefits to service users and carers and is perhaps where the greatest change has occurred. Organisational change usually happens from the top down and rarely happens from the bottom up 'in the sense of starting from the initiative of users and carers' (Fletcher, 2006:74). It is clear that this project has gone some way to addressing the need for a 'bottom up' approach and the evaluation clearly highlights the benefits to service users in terms of improving confidence, participation, empowerment, having valued roles and recognising personal capacity and expertise, as well as overcoming some of the barriers identified by Beresford (2013).

User participation is crucial to the concept of a learning organisation, and the requirement to change and innovate in practice is necessary if organisations are to make connections between individual and organisational learning (Gould and Baldwin, 2004). Ultimately, we would want this model to be rolled out across a number of agencies, and service user groups or settings, and in the coming years will become an integral part of the practice learning agenda. In order to do so, organisations (including the University) need to be open to learning, open to power sharing, and use an action research model to adapt and refine the process and embrace the continual learning we can achieve, for the benefit of our students and most importantly to include and empower the people we support. The positive outcomes for students and especially for the project mentors would indicate that with a strong commitment to partnership working and with the willingness to provide the correct amount of preparation, planning and support, those service users with 
complex disabilities and whose voices are seldom heard, can overcome the barriers to involvement in social work education.

\section{References}

Alston, M and Bowles, W (2003) Research for Social Workers: An introduction to methods. (2nd ed.) London: Routledge

Anghel, R. and Ramon, S (2009) Service users and carers' Involvement in social work education: Lessons from an English case study', European Journal of Social Work, 12, 2, 185-199

Benbow, S.M., Taylor, L., Mustafa, N. and Morgan, K. (2011) Design delivery and evaluation of teaching by service users and carers. Educational Gerontology, 37, 621-633

Beresford, P. (2000) Service users' knowledge and social work theory: Conflict or collaboration? British Journal of Social Work, 30, 489-503

Beresford, P. (2013) Beyond the Usual Suspects., London: Shaping our Lives. www. shapingourlives.org.uk/documents/BTUSReport.pdf [accessed 20.10.14]

Branfield, F (2009) Developing User Involvement in Social Work Education. SCIE Report 29, London: SCIE

Brown, K and Young, N (2008) Building capacity for service user and carer involvement in social work education. Social Work Education, 27, 1, 84-96

Carpenter, J (2005) Evaluating Outcomes in Social Work Education. London and Dundee: SCIE and SIESWE

Duffy, J., Das, C. and Davidson, G. (2011) Service user and carer involvement in role plays to assess readiness for practice. Social Work Education: The International Journal, vol. 32, no. 1, pp. 39-54

Fletcher, K. (2006) Partnerships in Social Care: A Handbook for Developing Services. London: Jessica Kingsley Publishers

Gould, N and Baldwin, M (2004)(Eds.) Social work, Critical Reflection and the Learning Organisation. Aldershot: Gower

Levin, E (2004) Involving Service Users and Carers in Social Work Education, SCIE Guide 4, Bristol: the Policy Press

Molyneux, J and Irvine, J (2004) Service User and Carer Involvement in Social Work Training: a long and winding road?, Social Work Education, 23:3, 293-308

Parker, J. (2004) Effective Practice Learning in Social Work ${ }^{\text {nd }}$ Ed. Exeter: Learning Matters Ltd Petr, CG and Walter, UM (2009) Evidence based practice: A critical reflection, European Journal of Social Work,12:2, 221-232

Sanderson, H..et al (1997) People, Plans and Possibilities. Edinburgh: SHS Ltd

Scottish Executive (2006) Report of the 21 ${ }^{\text {st }}$ Century Social Work Review: Changing Lives. Edinburgh: Scottish Executive

Scottish Executive (2003) The Framework for Social Work Education in Scotland. Edinburgh: 
Scottish Executive

Skilton, CJ (2011) Involving experts by experience in assessing students' readiness to practise: the value of experiential learning in student reflection and preparation for practice. Social Work Education, 30, 3, 299-311

Stevens, S. and Tanner, D. (2006) Involving service users in the teaching and learning of social work students: Reflections on experience. Social Work Education, 25, 4, pp. 360-371 Trevithick, P (2008) Revisiting the Knowledge Base of Social Work: A Framework for practice, British Journal of Social Work, 38, 1212-1237

Warren, J. (2007) Service User and Carer Participation in Social Work. Exeter: Learning Matters Whittaker, J. (2009) Research Skills for Social Work. Exeter: Learning Matters 